\title{
Stabilization of Terminal Voltage and Damping the Mechanical Angle Oscillations in Single-machine Infinite-bus Power System Using MISO Fuzzy Controllers
}

\author{
Muhammad M.A.S. Mahmoud \\ IEEE Senior Member, Professor, Independent Researcher and Freelance Consultant, Cairo Egypt
}

\begin{abstract}
This article proposes new fuzzy controller to regulation the voltage, damp the oscillations and limit the overshoot behavior in single-machine infinite-bus power system. Two different independent MISO fuzzy controllers are designed. First controller, is voltage stabilizer and it composes of two adaptive fuzzy modules and proportional gain AVR. The voltage stabilizer is designed to regulate the terminal voltage, damp the voltage oscillation and limit the voltage overshoot to the industrial maximum allowable limit. The input signals of this stabilizer is are taken from the terminal voltage and the imposed voltage disturbance that can be read from any smart relay. The fuzzy output is used as feedback signal to control the AVR in order to achieve stabilized voltage equal to the reference voltage. The second fuzzy controller is designed with two input signals; "mechanical angle" and its derivative, and one output which is used as feedback signal to adapt the damping torque in order to damp the mechanical oscillation fast and with maximum overshoot not exceeding $10 \%$, and hence damp the power angle oscillation that is important in the PSS improvement. MATLAB-SIMULINK was used for modelling and the test cases simulation. The results show very good performance for the proposed fuzzy controllers.
\end{abstract}

Keywords: Fuzzy control, PSS, AVR, mechanical angle, power angle, oscillation damping, adaptive control.

\section{Introduction}

The ability of the power system to return to its normal or stable conditions after being disturbed is called stability. Disturbances of the system may be noticed in the network frequency or voltage or both together due to different reasons like sudden changes of load, the sudden short circuit between line and ground, line-to-line fault, all three line faults, switching, etc... [1].

The application of fuzzy logic control techniques appears to be most suitable one whenever a well-defined control objective cannot be specified, the system to be controlled is a complex one, or its exact mathematical model is not available. Therefore, it was found that fuzzy logic is very suitable technic to be used in PSS problems. Hereinafter the paper will highlight important work that have done in PSS. In this section we will come across some of selective reaches on PSS control that have used fussy logic in the last 20 years.

In [2], the paper investigates the robustness of fuzzy logic power system stabilizers using the information of speed and acceleration states of a study unit. The input signals are the real power output and/or the speed of the study unit. Nonlinear simulations show the robustness of the fuzzy logic power system stabilizers. Experiments are also performed by using a micro-machine system. The results show the feasibility of the proposed fuzzy logic stabilizer. In [3], the PSS approach is based on the traditional frequency domain method. In addition, a fuzzy signal synthesizer is introduced to achieve adaptiveness. Two linear stabilizers are designed to accommodate two extreme loading cases. A fuzzy logic mechanism is used to generate one control signal by properly combining the outputs of the linear stabilizers. The fuzzy controller is optimized using a least squares error criterion. This approach does not consider the voltage regulation. In [4], both the AVR and PSS are considered in are designed, realistic control specifications such as the rise time and the overshoot of step responses were given. The PSS structure and the lead-lag compensator formulas were provided to allow selecting the PSS parameters. In [5], a design scheme for fuzzy 
logic power system stabilizer for multi-machine power system with 10 busses has been developed using speed deviation and acceleration of synchronous generator as inputs to the fuzzy logic controller. The results improved the marginally the oscillation of the system. In [6], a new power system stabilizer is developed and called Multi-Band Power System Stabilizer (MB-PSS). It is based on multi-frequency variables that stabilizer can obtain to cope with all low, intermediate, and high oscillations frequencies.

Fuzzy logic is also used in many Hierarchal process control applications [7-10]. However, in [11] a rule-based hierarchal Fuzzy PSS is designed. Its parameters are tuned by another fuzzy logic system, making it adaptable to changes in operating conditions. Then it is used to stabilize a synchronous machine, which is part of a multi-machine power system and the power system stabilizers (PSSs) are implementation at each machine. In [12], the paper presents a new power system stabilizer with an adaptive PID fuzzy controller for different operating conditions of the power system. Various simulations have been performed in order to subject it to several types of large disturbances using a single-machine infinite bus power system. In [13] fuzzy power system stabilizers are added to the control loop of the generating unit to enhance the damping during low frequency oscillations. speed deviation and acceleration of the rotor of synchronous generator were taken as the input to the fuzzy logic controller. These variables produce significant effects on damping of the generator shaft mechanical oscillations.

Sliding mode control is one of the main methods employed to overcome the uncertainty of the system. This controller can be applied very well in presence of both parameter uncertainties and unknown nonlinear function such as disturbance. In [14], power systems stability is enhanced through a stabilizer developed around a fuzzy sliding mode approach. First, sliding mode control is applied to selected operating point based models of a power system separately then fuzzy logic is used to form a global model encompassing the separate subsystems, thus leading to a fuzzy sliding mode power system control. However, the controller is designed mainly to network frequency stability. In [15], to enhance stability and improve dynamic response of the system operating in faulty conditions a Fuzzy based sliding mode control power system stabilizer is developed for a multi-machine system with two generators. But, the result for voltage response show unacceptable overshoot in voltage and power, which can cause tripping of the network in overvoltage or overload. In [16], the paper investigates three control strategies to design an efficient PSS for the power network, including a PID-based PSS, a fuzzy logic - based PSS (FLC), a fuzzy logic-integrated sliding mode control- based PSS (SMC). From this investigation, it was found that FLC and SMCbased PSS regulators have excellent responses with small oscillations and short response time, while the PID controller obtains large deviations and greater response time.

Small signal oscillations can be also effectively damped using fuzzy power system stabilizers. In [17], the paper Fuzzy Logic Power System Stabilizer (FLPSS) is designed to damp low frequency oscillations and improve the stability of the power system. Speed deviation and accelerating power are taken as inputs to the FLPSS. The result does not show significant enhancement in the voltage response compared with conventional controller. In [18], a linearized Heffron-Philips model of a Single Machine Infinite Bus (SMIB) power system with a Fuzzy Logic Power System Stabilizer (FPSS) is developed for different membership functions. For FPSS, similar in many papers, speed deviation and acceleration deviation are taken as inputs. Also, the paper concentrated in frequency control only and did not proposed voltage regulation control. In [19] the article investigates the coordination and optimization of fuzzy controllers for designing PSS and STATCOM controllers for more attenuation of power system frequency fluctuations.

For interconnected network, in [20] the research presents the analysis of change of speed, change of angle position and tie - line active power flow in two area symmetrical systems connected via tie-line using fuzzy logic controller (FLC), without examining the voltage oscillation in the network. But in [21], the stability of the interconnected power network improvement considers the power delivered from wind turbine. The aim of this research is to improve stability of power system interconnection with new wind turbine plant added in two different areas. In this research, there are two problems that are evaluated, namely the stability of the system before and after the penetration of wind turbine to the network. Conventional PSS signals are added to control the Stability System at naturally occurring operating points, this limits PSS performance and robustness. 
To solve this deficiency, FLC controller is proposed. But, the result showed that still tuning in the Fuzzy PSS is required to reduce the oscillation.

From the above comprehensive survey for the researches that were conducted on PSS using fuzzy controllers in the last 20 years, it is obvious that the low frequency oscillations have always been the main problem of power system and can lead to power angle instability. For boosting power system stability limits, the most effectiveness way is to install with the PSS to damp the fluctuation of the power angle oscillation, a supplementary excitation control to add a supplementary feedback stabilizing signal into the automatic voltage regulator (AVR). Therefore, this paper focusses on the voltage and power angle oscillation damping by proposes two fuzzy controllers for typical power system model. The first controller damps the voltage oscillation, and the second controller damps the oscillation in the power angle.

In Section 2, the base system for power network model that shall be used in this article is presented. Section 3 introduces the fuzzy controller for voltage stability and damping the voltage oscillation. In section 4, fuzzy controller for damping the mechanical angle oscillation, and hence the power angle oscillation, is presented. Finally, conclusion is given in Section 5 .

\section{Power System Modeling}

Stability is classified into rotor angle, voltage and frequency stability they need not be independent isolated events. A voltage collapse at a bus can lead to large excursions in rotor angle and frequency. Similarly, large frequency deviations can lead to large changes in voltage magnitude. Therefore, main component of the power system i.e. prime mover, generator rotor, generator stator, transformers, transmission lines, load, controlling devices and protection systems should be mathematically represented to assess the rotor angle, voltage and frequency stability through appropriate analysis tools [2].

The model, which is used in this article for the design of the PSS, consists of a single generator that supply its electrical power $(\mathrm{Pe})$ to the infinite bus. This system named "single-machine infinite bus". The schematic diagram of this system is shown in Fig. 1

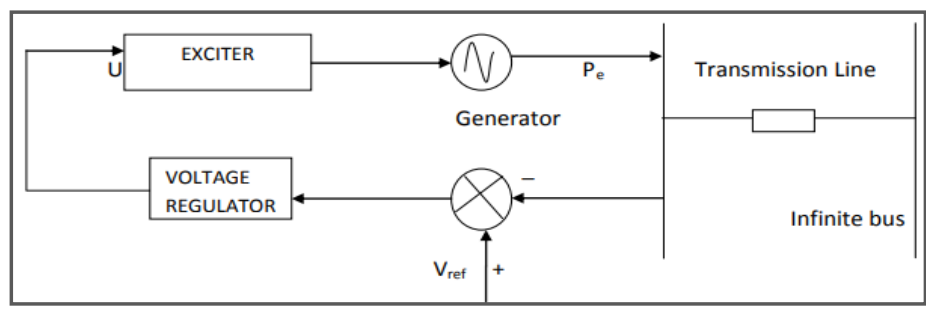

Figure1: Single-machine infinite-bus system

In this system, the voltage regulator controls the exciter voltage input (u), and hence, the field voltage to maintain the synchronous generator terminal voltage at the desired value (Vref). The state -space representation of this system is described as following [23]:

The state variables for the system are $x=\left[\delta \omega E_{q}^{\prime} \psi_{d} E_{d}^{\prime} \psi_{q} V_{r}\right]^{\top}$. The input variable is $u=V_{r e f}$

The output variables are $y=\left[V_{\text {term }} \omega \mathrm{Pe}_{\mathrm{e}}\right]^{\top}$, Where,

$\delta=$ rotor angle in radian.

$\omega=$ angular frequency in radian/sec.

$\Psi_{\mathrm{d}}, \mathrm{E}_{\mathrm{d}} \mathrm{d}=$ direct axis flux and field.

$\Psi_{\mathrm{q}}, \mathrm{E}_{\mathrm{q}}^{\prime}=$ quadrature axis flux and field

$V_{\text {term }}$ terminal voltage

$\mathrm{P}_{\mathrm{e}}=$ Power delivered to the infinite bus.

The power system model is linearized at a particular equilibrium point to obtain the linearized system model given in the state-space form (1):

$$
\Delta \mathrm{x}^{\prime}=\mathrm{A} \Delta \mathrm{x}+\mathrm{B} \Delta \mathrm{u} ; \quad \Delta \mathrm{y}=\mathrm{C} \Delta \mathrm{x}
$$

where $\Delta$ denotes the perturbation of the states, input, and outputs from their equilibrium value.

The following matrices of the state space form are obtained from typical machine parameters: 
$\mathrm{A}=\left|\begin{array}{ccccccc}0 & 376.99 & 0 & 0 & 0 & 0 & 0 \\ -0.246 & -0.156 & -0.137 & -0.123 & -0.0124 & -0.0546 & 0 \\ 0.109 & 0.262 & -2.17 & 2.30 & -0.171 & -0.0753 & 1.27 \\ -4.58 & 0 & 30.0 & -34.3 & 0 & 0 & 0 \\ -0.161 & 0 & 0 & 0 & -8.44 & 6.33 & 0 \\ -1.70 & 0 & 0 & 0 & 15.2 & -21.5 & 0 \\ 33.9 & -23.1 & 6.86 & -59.5 & 1.5 & 6.63 & -114\end{array}\right|$

$\mathrm{B}=\left|\begin{array}{llllllll}0 & 0 & 0 & 0 & 0 & 0 & 0 & 16.4\end{array}\right|^{\mathrm{T}}$

$\mathrm{C}=\left|\begin{array}{ccccccc}-0.123 & 1.05 & 0.23 & -0.207 & -0.105 & -0.460 & 0 \\ 0 & 1 & 0 & 0 & 0 & 0 & 0 \\ 1.42 & 0.9 & 0.787 & 0.708 & 0.0713 & 0.314 & 0\end{array}\right|$

Following is MATLAB- SIMULINK [24] block diagram that present the voltage control loop for the base model I (Fig.2). This presentation shall be used hereinafter to deigned the required fuzzy controller for voltage oscillation damping.

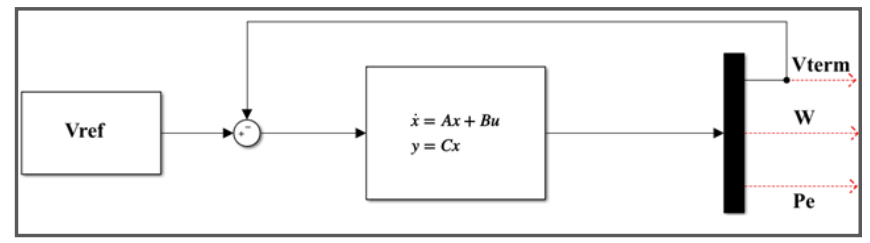

Figure.2. Base model voltage control loop

Fig.2: Base model voltage control loop

However, for the deigned the required fuzzy controller for power angle oscillation damping, decompose the power system model to isolate the $H(s)$ state-space model that its input is the machine speed $(\omega)$ and is and its output is the electrical torque. The resultant $A$ matrix with decision is as following:

$$
\mathrm{A}_{\mathrm{dc}}=\left|\begin{array}{ccc}
0 & 376.99 & 0 \\
-S & -D & a_{2 a} \\
a_{31} & a_{32} & A_{a 3}
\end{array}\right|
$$

Where $(S)$ is the synchronization torque factor, (D) is the damping factor, $\left(a_{23}\right)$ is a row vector, and $\left(\mathrm{a}_{31}\right)$ and $\left(\mathrm{a}_{32}\right)$ are column vectors, and $A_{33}$ is a square matrix. The values $A_{d c}$ elements can be found simply by comparing $\left(A_{d c}\right)$ matrix with $(A)$ matrix. The decomposed state space can be written in the following form:

$$
\eta \dot{\eta}=A_{33} \eta+a_{32} \omega, \quad T=a_{23} \eta
$$

The block diagram of the decomposed system is shown in following MATLAB-SIMULINK Fig.3.

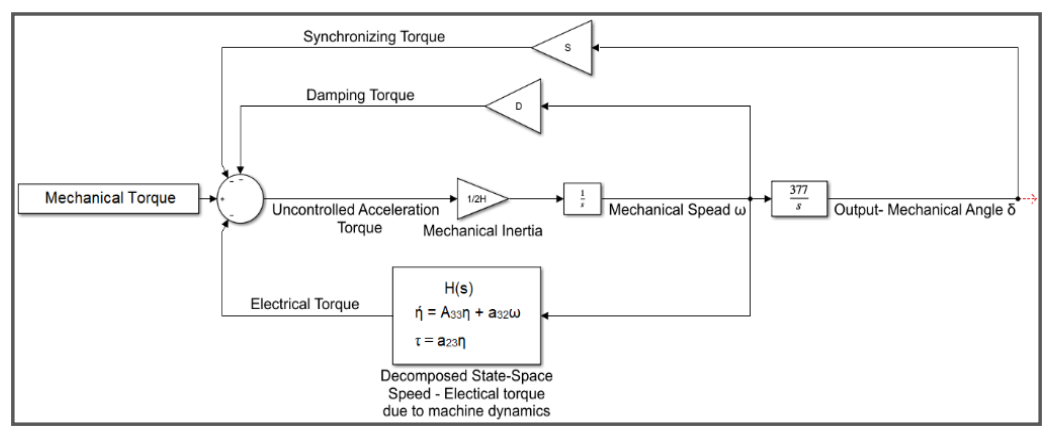

Figure 3. Decomposition of speed control loop 
In order to design the fuzzy controller to damp the power angle and voltage oscillations, first, the response of the control loop of base model and decomposed model need to be studied.

\subsection{Base Model voltage control loop Response:}

In order to study the response of the voltage control loop of the base model (Fig 2), step voltage input is applied at to the $\mathrm{V}_{\text {ref }}$, and the output $\mathrm{V}_{\text {term }}$ is recorded. Fig.4 illustrates the response of the terminal voltage, and shows that the $V_{\text {term }}$ reaches stable steady state condition with approximately 0.54 error.

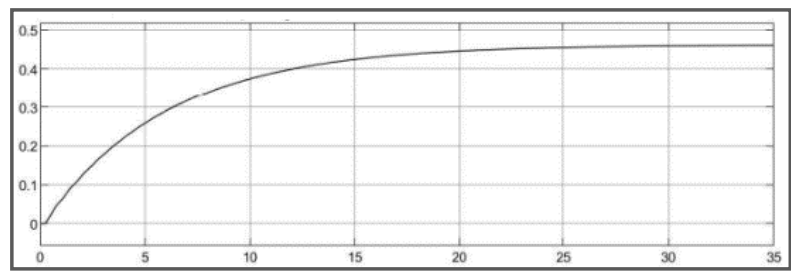

Figure 4. $\mathrm{V}_{\text {term }}$ response with Step input $\mathrm{V}_{\text {ref }}$

\subsection{Decomposed Model Response:}

In the decomposed model, with different values of mechanical input, we can record the corresponding synchronizing torque, damping torque and the output mechanical angle ( $\delta)$. Fig.5 illustrates the response for these variables when the input (mechanical torque) is changed in steps from zero to 20 .

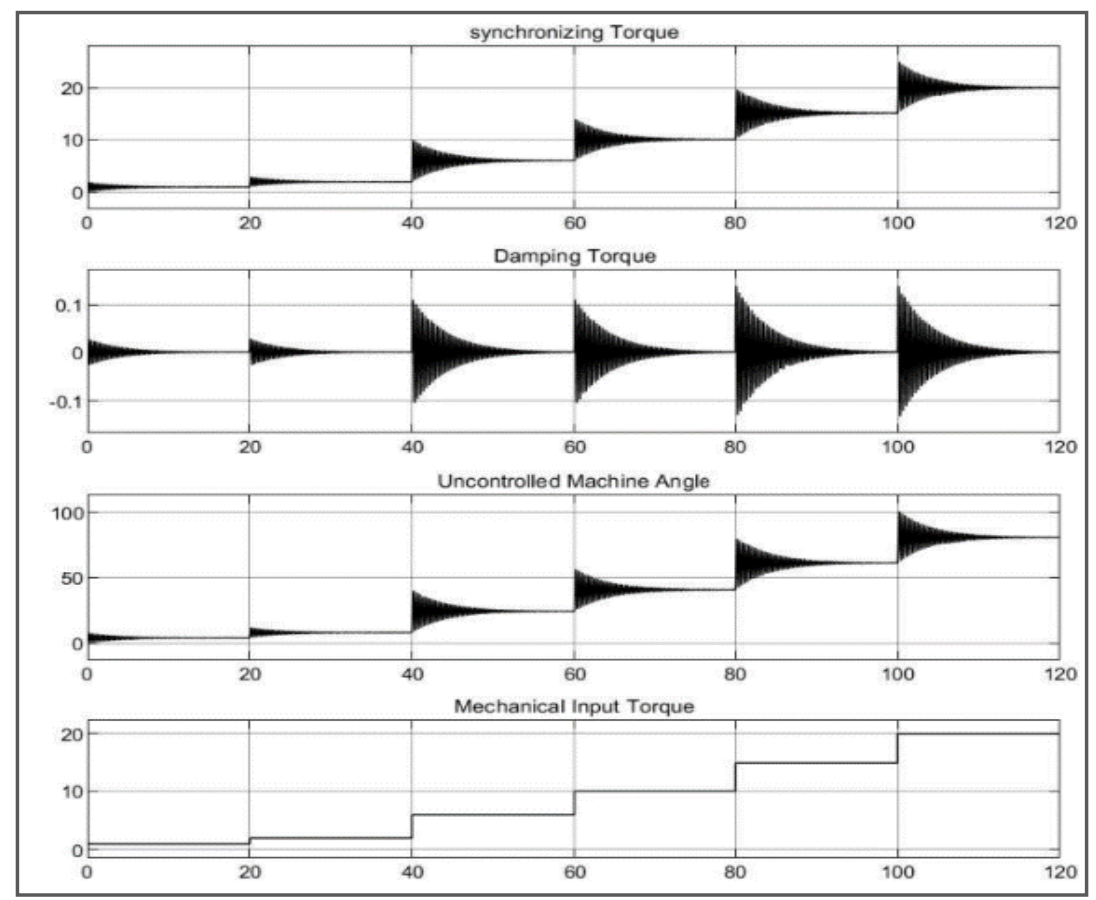

Figure 5. Decomposed model response with input (mechanical torque) changes in steps from zero to 20.

\section{Fuzzy controller for voltage stability}

Retrieving the $\mathrm{V}_{\text {term }}$ response with step input $\mathrm{V}_{\text {ref }}(\mathrm{Fig}, 4)$, this type of response can be enhanced usually using traditional PID controller. However, in this article combined proportional technique only with fuzzy logic controller are used to design the voltage stabilized. 
In [4]. PID controller is used with $P=35$. The accuracy, oscillation and damping problems are solved using optimum integration and differentiation controllers. In this article, first, the model is evaluated with proportional gain $\mathrm{P}=35$ and higher as an AVR based on proportional gain techniques. The selective criteria of the proportional gain value is to reach Zero error and to limit the overshoot to 1.2PU approximately, as this is the value that always acceptable in industry [24]. The block diagram and the step response result for the model are shown in Fig. 6. And Fig. 7.

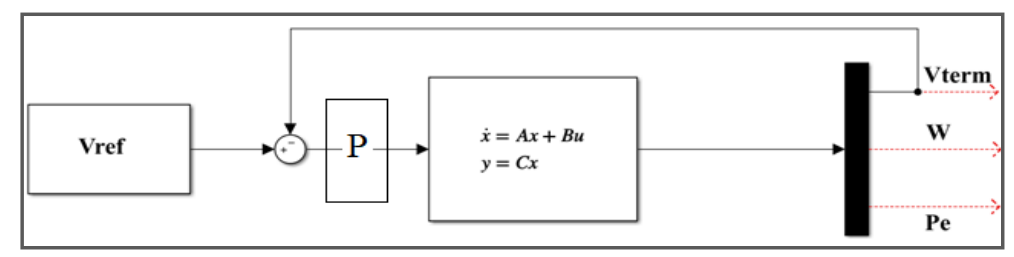

Figure 6. Base model with Proportional AVR

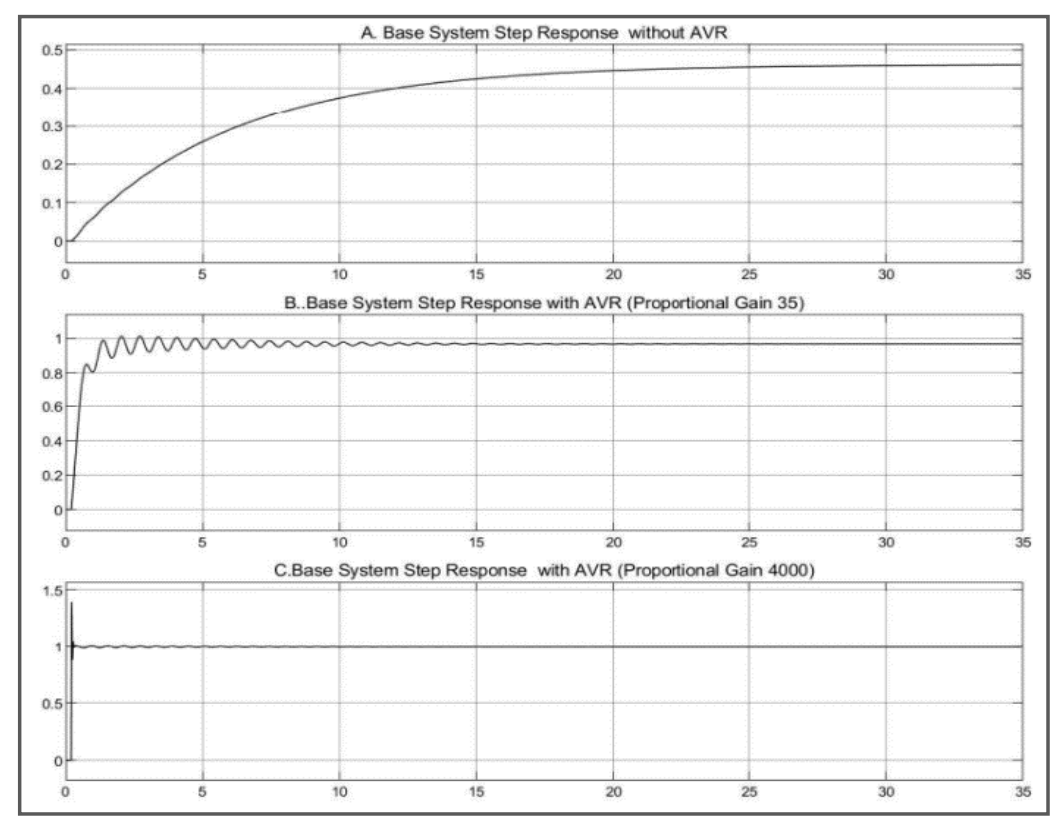

Figure 7. Base system step response with different proportional gain values as AVR

The result shows that using proportional gain $\mathrm{P}=35$ as $\mathrm{AVR}$ gives marginally acceptable results with $-0.035 \mathrm{PU}$ error, overshoot of $0.013 \mathrm{PU}$ and oscillation for 8 second. However, for proportional gain of $\mathrm{P}=4000$ as $A V R$, the result shows no error, negligible oscillation and overshoot of approximately $0.2 \mathrm{PU}$. This result is satisfactory to start design the fuzzy controller to damp the overshoot and the oscillation if any.

In this stage, the power system model behavior with proportional gain of $P=4000$ as AVR needs to be tested under voltage disturbance from 0 to $1.2 \mathrm{PU}$ imposed on $\mathrm{V}_{\text {term }}$ with $\mathrm{V}_{\text {ref }}=1 \mathrm{PU}$ (Fig 8. and Fig. 9).

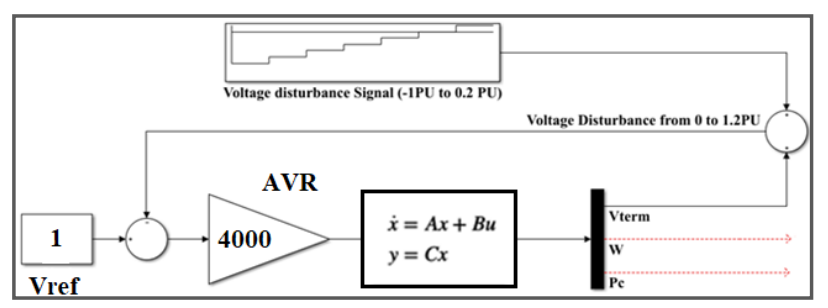

Figure 8. Power system block diagram under voltage disturbance from 0 to $1.2 \mathrm{PU}$ imposed on $\mathrm{V}_{\text {term }}$ 


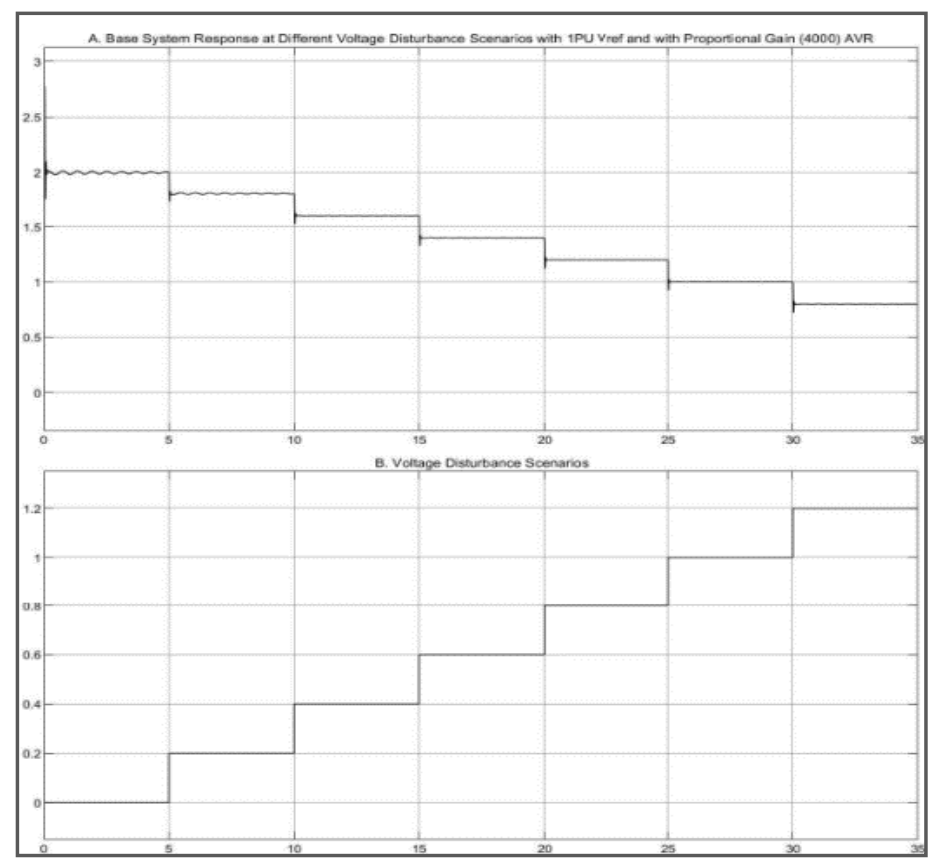

Figure 9: Power system response under voltage disturbance from 0 to $1.2 \mathrm{PU}$ imposed on $\mathrm{V}_{\text {term }}$

From the result of this test, the first stage of feedback fuzzy controller can be designed for terminal voltage stability. Fig. 10 illustrates the fuzzy feedback controller that is proposed to control the terminal voltage and damp the oscillations.

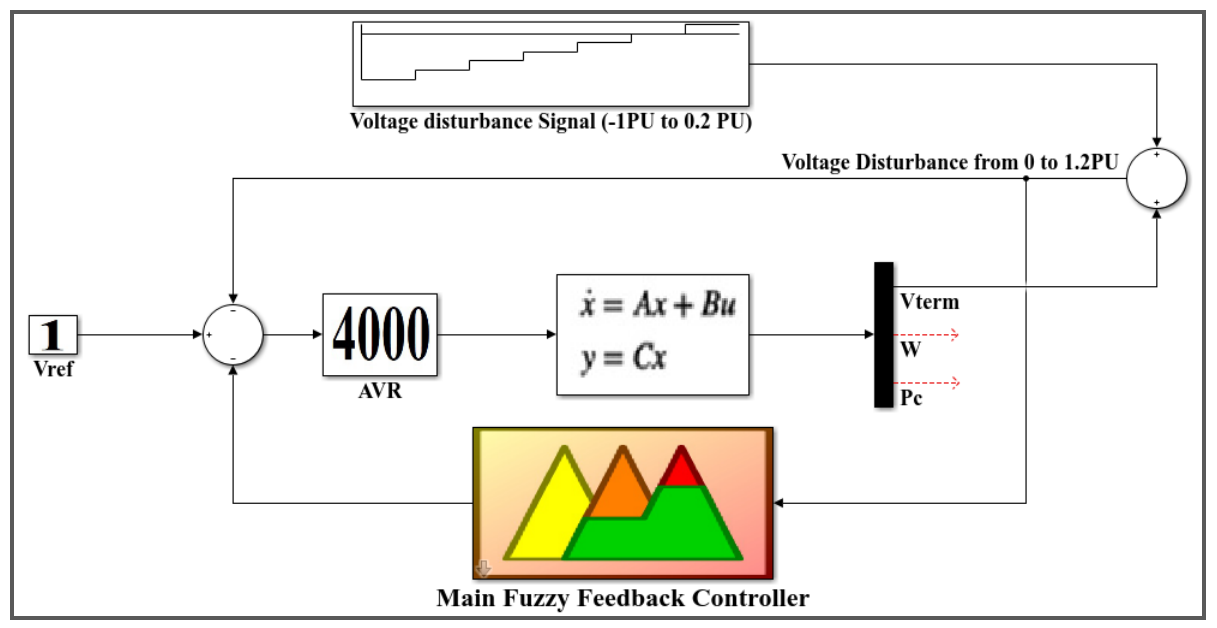

Figure 10. Fuzzy feedback control for voltage stability

For this fuzzy controller, input membership functions range is selected based on the disturbance in the voltage from 0 to 2 , as this is the fluctuation range of the terminal voltage, and it can be read from any smart protection relay. The output range of the membership functions is taken from -1 to 1 with linear inverse rule to compensate the voltage disturbance with 9 membership function for both output and input. In order to achieve linearity, the setup of this fuzzy controller considers; nine rectangular fuzzy memberships for "Input" and "Output", "Min" for "And", "Sum" for "Aggregation and "L.O.M" for "Defuzzification". This fuzzy feedback controller is tested with sever voltage drop disturbance (100\%) imposed on the power system, and without using any technique to damp either the overshoot or the oscillation. The result is illustrated in Fig.11. 


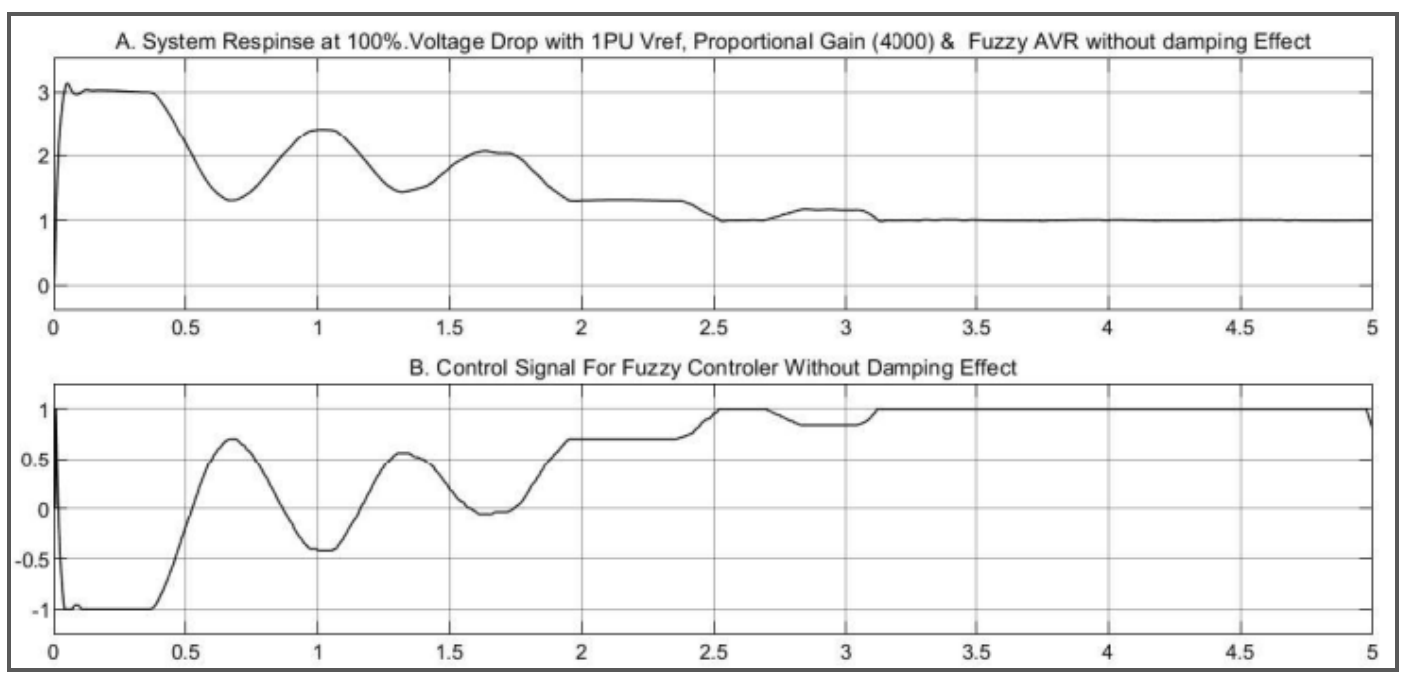

Figure 11. Fuzzy controller test with sever voltage drop disturbance (100\%) imposed on the power system.

The result shows clearly that the controller sends proper signal to the AVR to stabilize the voltage to the $V_{\text {ret }}$ value. But, it also clear that this fuzzy controller module, by itself, failed to damp the overshoot and the oscillation. Therefore, it is required to design anther fuzzy controller module. The function of this new module is to adapt the feedback signal in order to damp the overshoot and the oscillation.

The input membership functions range of this adaptive fuzzy module can be taken equal to the range of the overshoot from 1 to 3 . The output of range is selected to damp any oscillation that cause the measured terminal voltage to be higher than the reference voltage value. Base on this, the output membership functions range is from -2 to 0 . But in order to cover reasonable extended range for overshoot considering the maximum negative oscillation values, the range of the input membership function is extended to be from 0 to 3 and the range of the output membership function is also extended to be from -2 to 1 . This insures that whatever the "input" signal value is, a fuzzy rule is fired, and hence obtain "output" signal. The setup of the adaptive module is taken similar to the main fuzzy controller module, however in this module $100 \mathrm{~ms}$ delay in the sampling time is applied to allow the second fuzzy module to adapt the feedback control signal. Then the output signal of the adaptive module is subtracted from to the main feedback fuzzy controller signal. Fig. 12 illustrates the schematic diagram of the final fuzzy based voltage stabilizer.

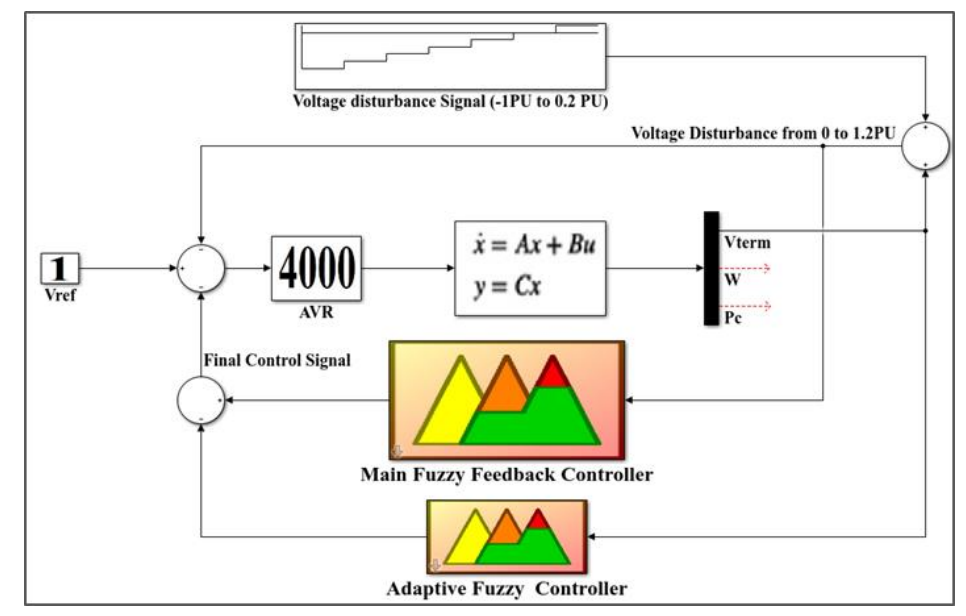

Figure12.: Final configuration of the feedback fuzzy voltage stabilizer 
In the beginning, this final configuration of the feedback fuzzy voltage stabilizer is tested with maximum disturbance in terminal voltage (100\% voltage drop). Then, for full satisfaction of the performance of the controller, final test is done with full range of terminal voltage disturbance from 0 to 1.2PU, and reference voltage of 1PU. The result is illustrated in Fig. 13 and Fig. 14 respectively.

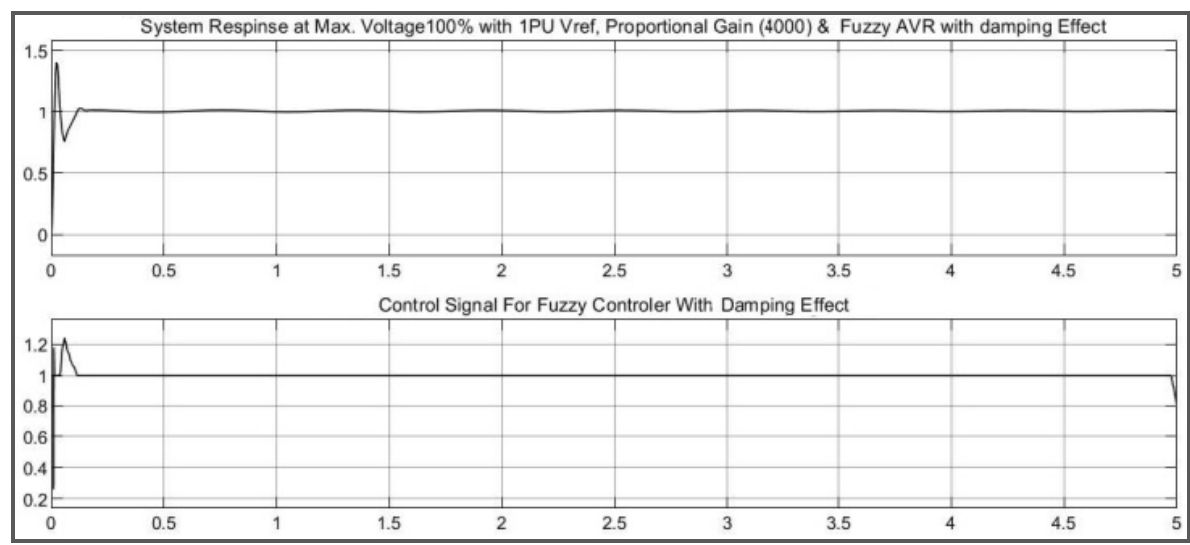

Figure 13. Fuzzy voltage stabilizer test with maximum disturbance in terminal voltage (100\% voltage drop)

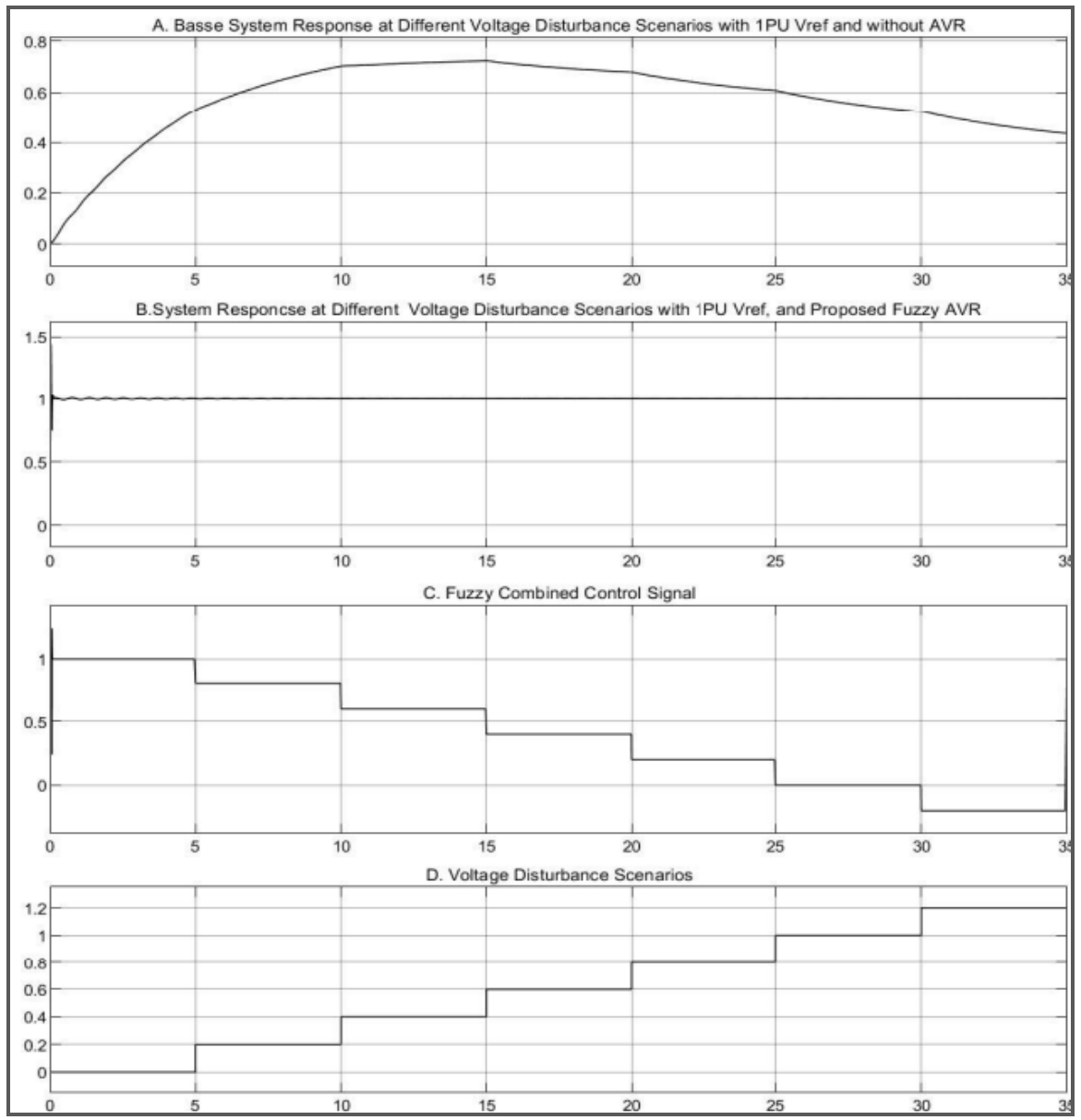

Figure 14. Final test with full range of terminal voltage disturbance from 0 to $1.2 \mathrm{PU}$, and reference voltage of 1PU 
From the final result, it can be seen that the proposed fuzzy voltage stabilizer with proportional gain AVR succeeded to regulate the terminal voltage to be equal to the reference voltage. Also, with initial value of terminal voltage equal "zero", the fuzzy voltage stabilizer not only regulates the voltage but also damps the overshoot to less than $0.2 \mathrm{PU}$ and drastically damps the oscillations to very acceptable levels.

\section{Fuzzy control for damping mechanical angle oscillations:}

By recalling the response illustrated in Fig 5 , it can be observed that at steady state synchronizing torque, damping torque and the output mechanical angle $(\delta)$ responses are stable, but have oscillations last for seconds before it reaches the steady state stability. As the synchronizing torque and damping torque are contributing in the calculation of the output mechanical angle $(\delta)$, so further investigation is required to determine the influence of these two torques on the output oscillations, and how much each torque contribute in the oscillation behaviour. For that four more test cases are required. The first two cases are to open the synchronization torque loop and observe the performance of the damping torque (Fig.15 and Fig. 16). The other case is vice-versa, open the damping torque loop and observe the performance of the synchronization torque. The second two cases are to observe the damping torque when the synchronization torque is zero and vice-versa (Fig.17 and Fig. 18).

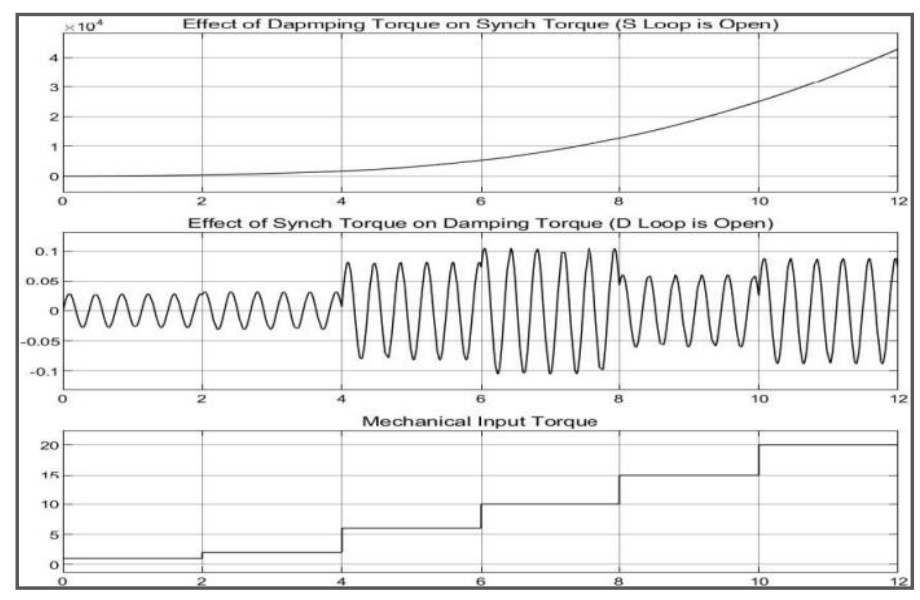

Figure 15. Effect of damping torque and synchronizing torque on each other

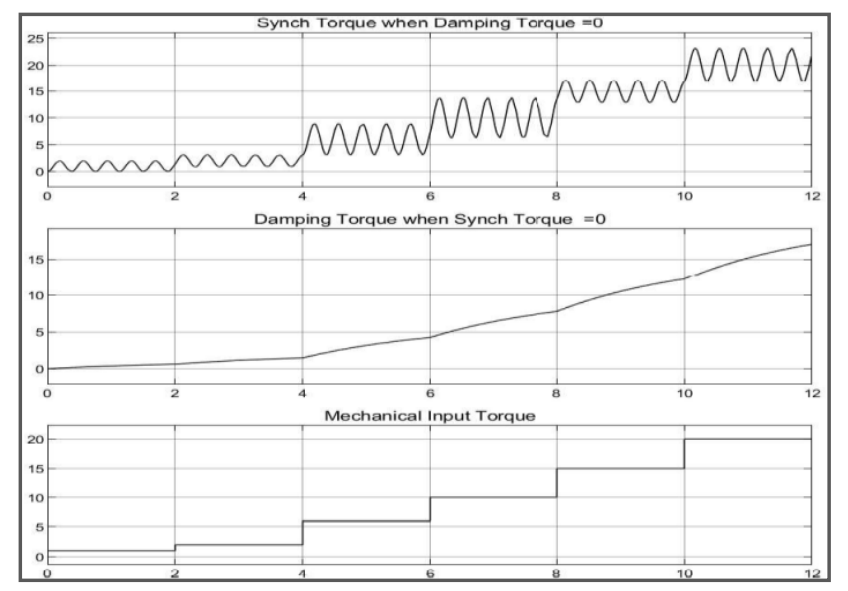

Figure 16. Damping torque and synchronizing torque values when each torque set to zero. 


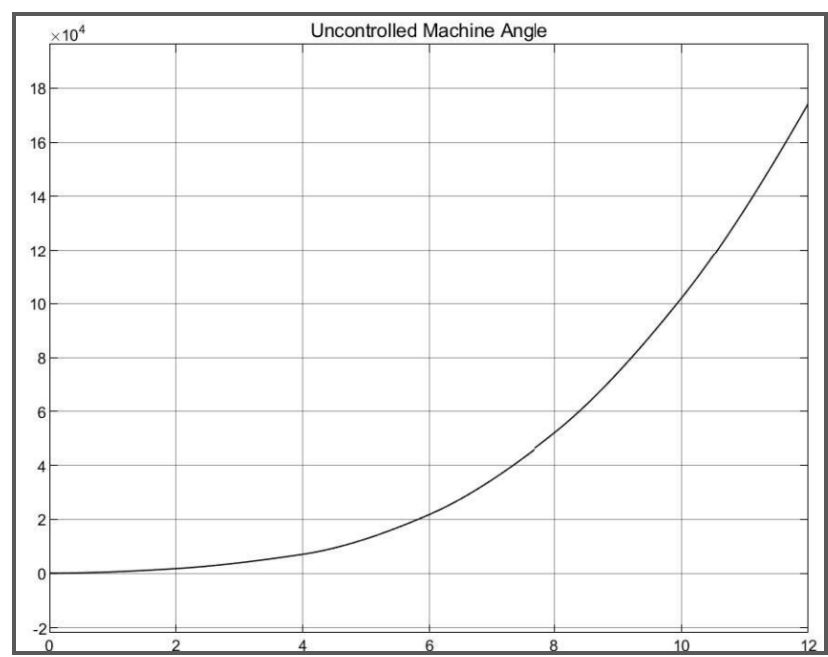

Figure 17. Uncontrolled mechanical angle when synchronizing torque Zero

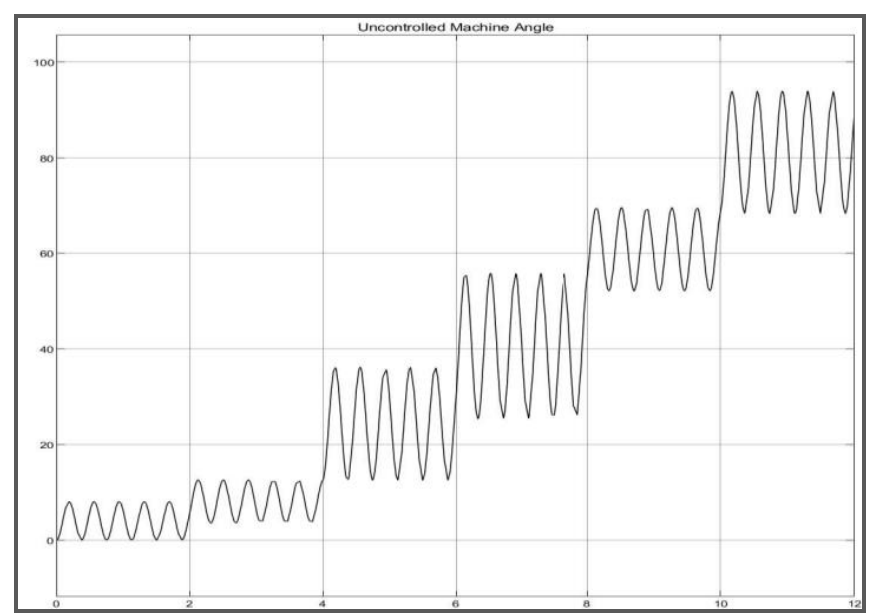

Figure 18. Uncontrolled mechanical angle when damping torque is zero.

From Fig.15 to Fig.18, it can be concluded that the damping torque contribute drastically in the causing of the oscillations much more than synchronizing Torque. However, synchronization torque is responsible of the stability., This conclusion comes from the fact that when the damping torque loop is open (damping toque = zero) the mechanical angle response is stable but oscillation, and when the synchronizing loop is opened (synchronizing torque = zero), the mechanical angle response. become unstable. Therefore, in the design of fuzzy oscillation damping stabilized for mechanical angle, adapting the damping torque need to be considered.

It is important to highlight in this stage that fortunately, due to the very short electrical timeconstant for the voltage stabilizer system comparing with the mechanical time-constant for governor and synchronous generator, the two fuzzy controllers for Voltage stabilized and mechanical angle stabilizers need not to coordinate between them.

Two important criteria are considered in the design fuzzy oscillation damping stabilizer. The first one is to consider the mechanical angle amplitude which is proportional to the mechanical input torque and to limit the overshot to maximum $10 \%$. The second one is to consider the speed of the increase of the angle in order to damp the mechanical angle oscillations in a short time. This achieves reasonable power system stability during the transient conditions. Based on this design philosophy, the fuzzy oscillation damping stabilizer is designed with two inputs (average mechanical angle and its derivative with respect to time) and the output is the adaptive damping torque. Fig. 19. 


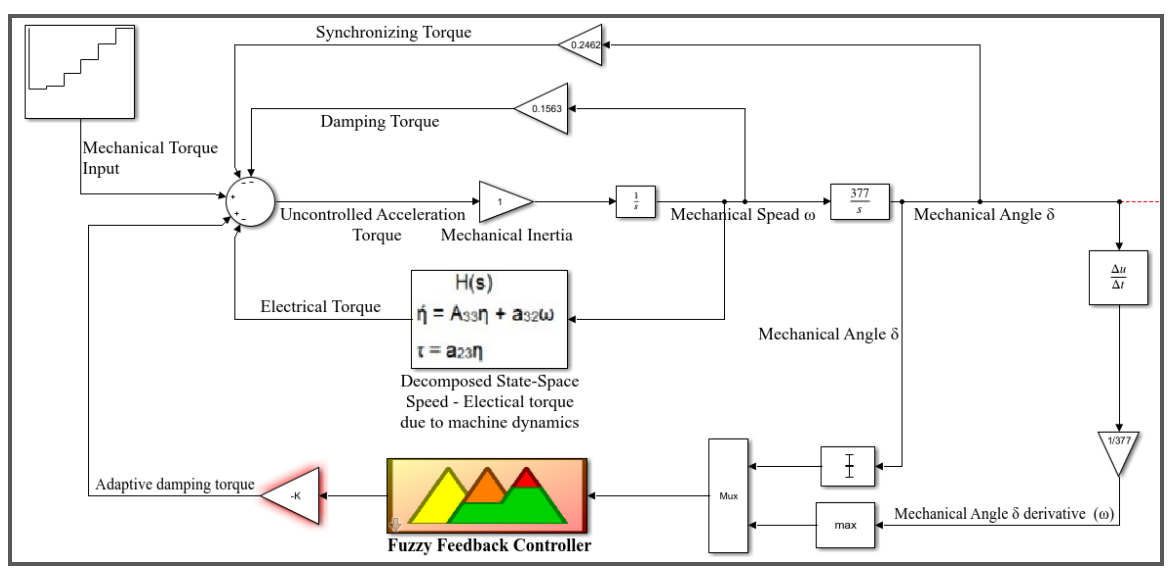

Figure 19. Configuration of the feedback fuzzy mechanical angle stabilizer

The first step, base decomposed model the required knowledge to design the required fuzzy stabilizer, open loop case study to determine the required adaptive damping torque that satisfies the design criteria was carried out and the result is given in Fig. 20 and Fig. 21.

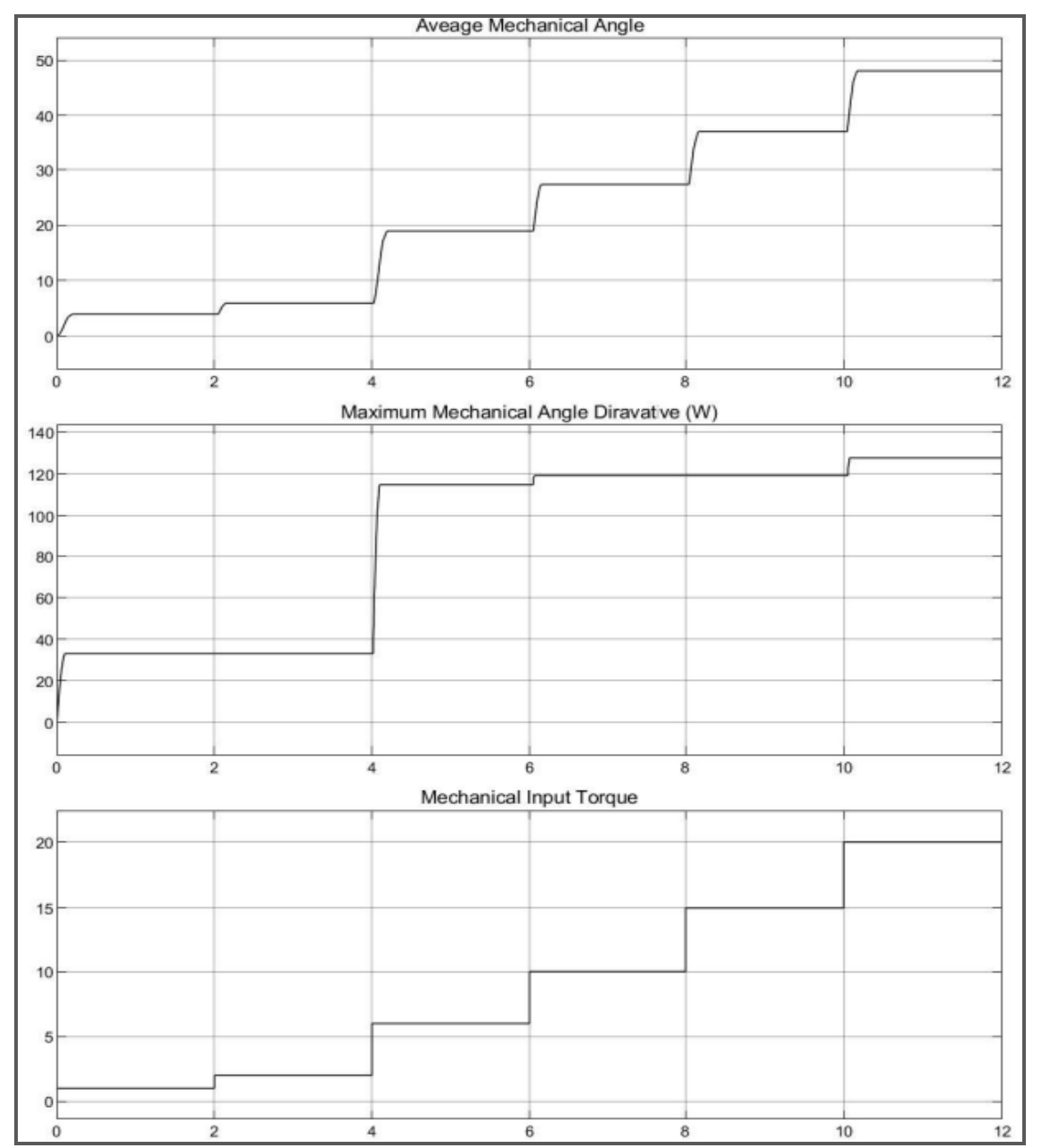

Figure 20. Average mechanical angle and it is maximum derivative 


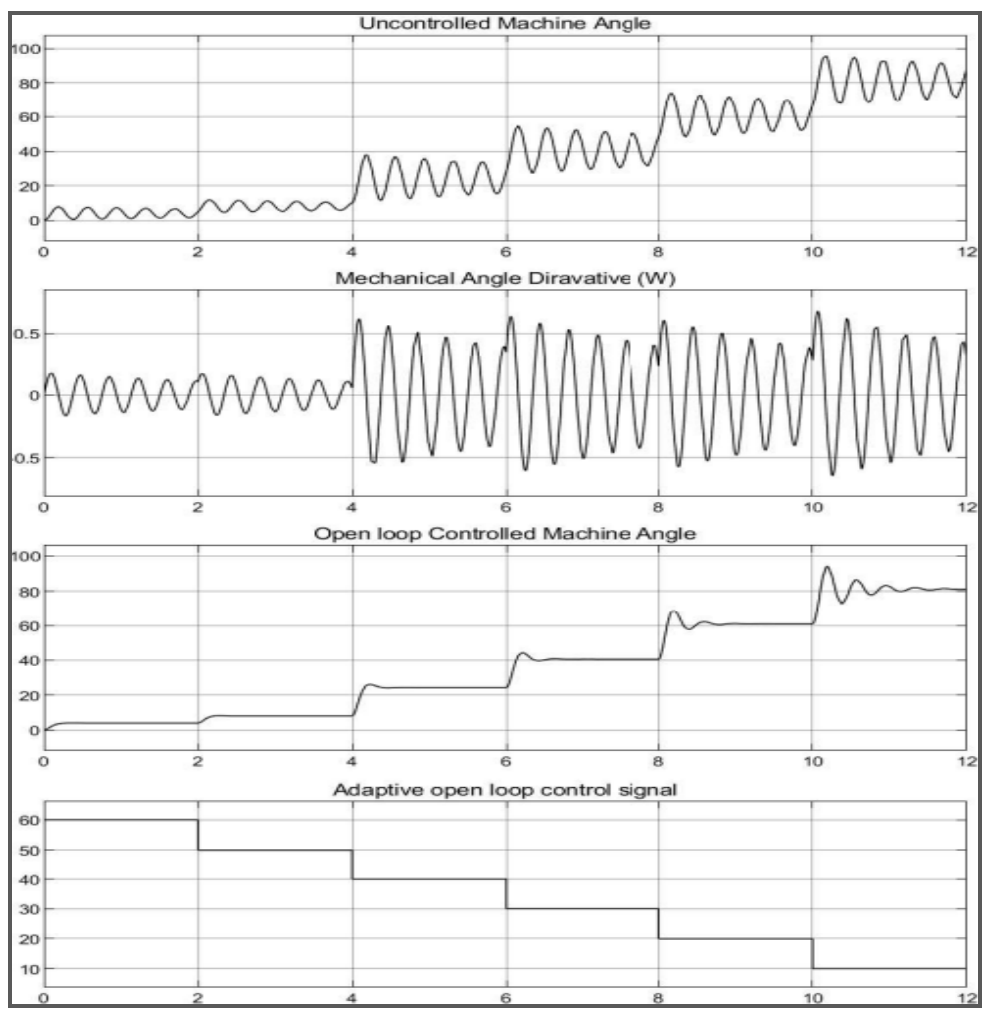

Figure 21. Open loop study case for the design of fuzzy mechanical angle stabilizer

In Fig. 20, the results show the response of the average mechanical angle and it is maximum derivative. Based on this figure, it is gives directive that the number of the fuzzy membership functions for the two input signals can be taken 6 for average mechanical angle and 3 for the its maximum derivative with triangle function shown in Fig. 22 and Fig. 23. However, based on Fig. 21 the number of the fuzzy input membership function is taken 6 with triangle function shown in Fig. 24.

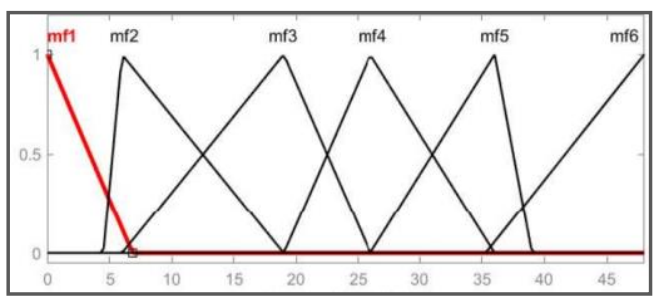

Figure 22. Control input 1: Average mechanical angle membership functions

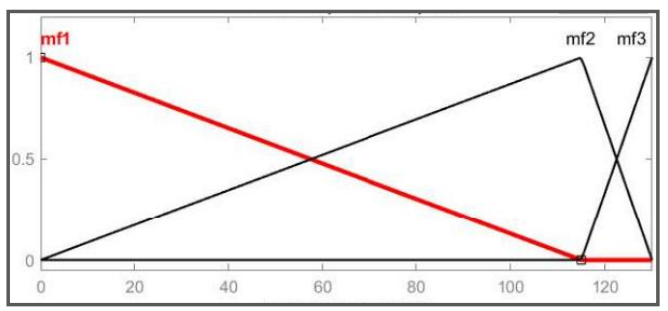

Figure 23. Control input 2: Maximum mechanical angle derivative membership functions 


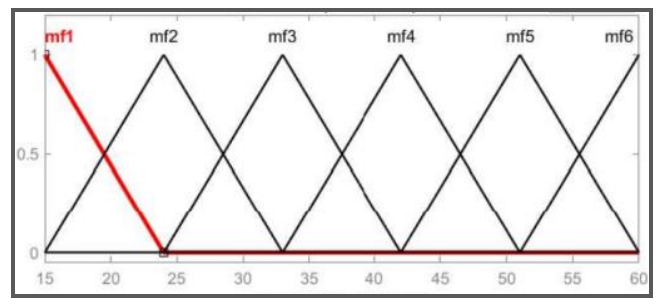

Figure 24. Control output: Fuzzy control output signal

The Fuzzy rule that are used in the fuzzy stabilizer of the mechanical angle is given in the Table 1.

Table 1: Fuzzy rules

\begin{tabular}{|c|c|c|c|c|c|c|c|}
\hline & & \multicolumn{6}{|c|}{$\begin{array}{c}\text { Input 1 } \\
\text { Maximum mechanical angle derivative membership functions }\end{array}$} \\
\hline & & $\mathrm{mf} 1$ & $\mathrm{mf} 2$ & $\mathrm{mf3}$ & $\mathrm{mf} 4$ & $\mathrm{mf5}$ & $\mathrm{mf} 6$ \\
\hline & & \multicolumn{6}{|c|}{ Fuzzy control output signal } \\
\hline \multirow{3}{*}{$\begin{array}{l}\text { Input } 2 \\
\text { Maximum mechanical } \\
\text { angle derivative } \\
\text { membership functions }\end{array}$} & $\mathrm{mf1}$ & mf6 & mf5 & mf5 & mf5 & $\mathrm{mf3}$ & $\mathrm{mf2}$ \\
\hline & $\mathrm{mf2}$ & $\mathrm{mf5}$ & mf5 & mf4 & mf3 & $\mathrm{mf2}$ & $\mathrm{mf2}$ \\
\hline & $\mathrm{mf3}$ & $\mathrm{mf5}$ & mf5 & mf4 & $\mathrm{mf2}$ & $\mathrm{mf2}$ & $\mathrm{mf1}$ \\
\hline
\end{tabular}

The remaining setup of this fuzzy controller considers; "Min" for "And", "Sum" for "Aggregation and "L.O.M" for "Defuzzification".

The controller is tested with wide input mechanical torque from 0 to 20. The result is illustrated in Fig. 25. From the results, we can observe that the fuzzy controller works properly to maintain the power system stability and to damp the oscillations of the mechanical angle, and hence damp the oscillations of the power angle as the relation between mechanical angle $\left(\theta_{\mathrm{m}}\right)$ and power angle $\left(\theta_{\mathrm{e}}\right)$ is $\theta_{\mathrm{e}}=0.5 \times \mathrm{P} \times \theta_{\mathrm{m}}$, where $\mathrm{P}$ is the number of poles.
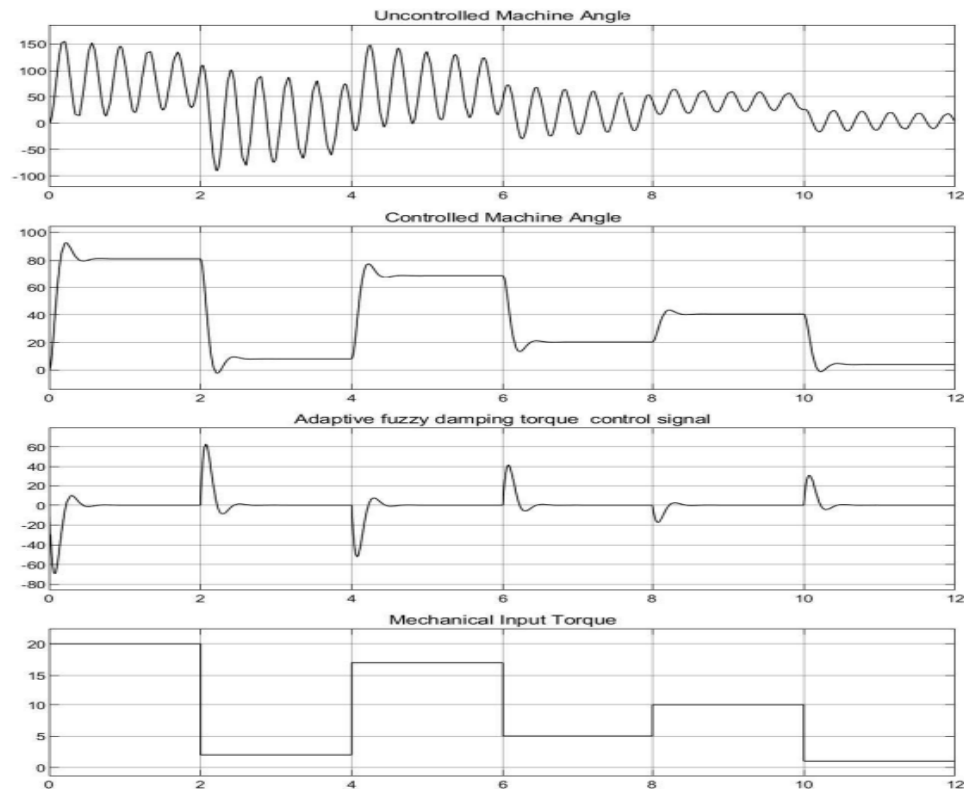

Figure 20. Fuzzy controller test for damping mechanical angle oscillation with mechanical torque input from 0 to 20 . 


\section{Conclusion}

In the introduction, the article comes across some of selective reaches on PSS control that have used fussy logic in the last 20 years. Then PSS enhancement for single-machine infinite bus system is introduced using two independent fuzzy-based controllers. The design of these controllers considered different operation scenarios. MATLAB-SIMULINK is used in the modeling the power system, estimation of the power its behavior and in the testing process.

The first controller is designed to include proportional gain AVR and two fuzzy modules that regulate the terminal voltage and damp the oscillations. Industrial requirements for maximum allowable overshoot is considered in the design of the controller. Two signals are taken for the input of this controller. The first input signal is the power system voltage disturbance signal and it can be taken from smart relay, and its controller module main function is to send a feedback signal to the proportional gain AVR to regulate the terminal voltage. The second module is adaptive module and its input signal is the terminal voltage and can be taken from voltage transformer (VT). The output of this module is as adaptive feedback signal that sent to AVR to limit the overshoot and damp the oscillation.

The second fuzzy controller for damping the mechanical angle is designed independently, as the mechanical time constant is much greater than the electrical time constant. Decompose model was used to isolate the required state space model which its "input" signal is "mechanical torque" and its "output" signal is "mechanical angle". From the analysis of the model performance, the second fuzzy controller is designed to have two input and one output in such a way to eliminate the oscillation introduced by damping torque, The input signals to the controller are taken from the average mechanical angle values and its derivative. The output signal of the controller is used as feedback signal to adapt the damping torque in order to fast eliminate the oscillation and limit the overshoot of the mechanical angle to maximum 10\%. Fuzzy rules are obtained from conducting study cases on the base composed model.

Comprehensive different test cases were carried out, and the result are illustrated. The results show very good improvement in regulating the power system terminal voltage, damping the oscillations and limit the overshoots to the industrial maximum acceptable level. Further development can be carried out using the same concept control to design synchronization relay.

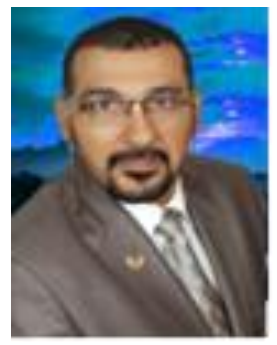

Muhammad M.A.S. Mahmoud, Egyptian, Received the B.S. degree in Engineering from Cairo University and the M.Sc. degree from Kuwait University. First Ph.D. degree from Transilvania University of Brasov, Romania in IT and Computer. Second PhD Degree in Electrical Power system and Machine, Cairo Univ. Egypt. He received a position of "Professor" on 2018. His current research interests in Fuzzy and Artificial Neural Network Techniques application include power delivery, protection reliability, control, safety, building automation and energy management. Prof. Dr. Muhammad is of IEEE Member in 1999, IEEE Senior Member (SM) since 2001 and TFS -IEEE Reviewer 2016.

\section{References}

[1] Muhammad M.A.S. Mahmoud. Zafar Qurbanov, Review of Fuzzy and ANN Fault Location Methods for Distribution Power System in Oil and Gas SECTORS, INTERNATIONAL Federation of Automatic CONTROL (IFAC 2018), ELSEVER

[2] T. Hiyama, "Robustness of fuzzy logic power system stabilizers applied to multi-machine power system," IEEE Transactions on Energy Conversion, vol. 9, no. 3, pp. 451-459, Sept. 1994, doi: 10.1109/60.326462.

[3] J. Lu, M.H. Nahrir, D.A. Pierre,"A fuzzy logic-based adaptive power system stabilizer for multi-machine systems", ELSEVIER Electric Power Systems Research, Volume 60, Issue 2, 2001.

[4] Joe H. Chow, George E. Boukarim, and Alexander Murdoch, "Power System Stabilizers as Undergraduate Control Design Projects", IEEE TRANSACTIONS ON POWER SYSTEMS, VOL. 19, NO. 1, February 2004.

[5] D.K. Sambaria and Rajeev Gupta, Fuzzy Logic Based Power System Stabilizer for Multi-machine System, National Power System Conference NPSC, pp 257-261 2004. 
[6] Youssef A. Mobarak, A Simulink Multi-Band Power System Stabilizer, Journal of Engineering Sciences (JES) Article 11, Volume 35, No 2, 2007, Page 489-507. DOI: 10.21608/JESAUN.2007.112354.

[7] Muhammad M.A.S. Mahmoud "New Area in Fuzzy Applications", Fuzzy Controllers Recent Advances in Theory and applications (Book), CHAPTER 17, PP $385-440$. INTECH, 2012. DOI: 10.5772/48781.

[8] Muhammad M.A.S. Mahmoud, "A new approach to fuzzy-control large scale systems", 12th WSEAS International Conference on Neural Networks, Fuzzy Systems, Evolutionary Computing \& Automation,

ISBN: 978-960-474-292-9, PP 161-168, BRASOV, 2012.

[9] Magdi S. Mahmoud, Manar M. Sabry, Salah G. Foda, "A New Approach to Fuzzy Control of interconnected Systems", Systems Analysis Modelling Simulation Pages 1623-1637, Published online: 29 Oct 2010.

[10] Muhammad M.A.S. Mahmoud, Damping of Surge Effects and Enhancement of Dynamic Response of Distillation plant using mimo fuzzy control, International Federation of Automatic CONTROL (IFAC 21018), ELSEVER.

[11] T. Hussein , A. L. Elshafei , A. Bahgat, Design of a hierarchical fuzzy logic PSS for a multi-machine power system, Mediterranean Conference on Control \& Automation, 2007 , pp 1-6.

[12] Jenica lleana Corcau, Eleonor Stoenescu, "Fuzzy logic controller as a power system stabilizer", International Journal of Circuits, Systems and Signal Processing, Issue 3, Volume 1, 2007.

[13] A. Taifour Ali, Eisa Bashier M Tayeb, Kawthar A. Adam, "A Multi-Machine Power System Stabilizer Using Fuzzy Logic Controller", International Journal of Computational Engineering Research, Vol. 2 Issue. 6, 2012.

[14] E. Nechadi and M.N. Harmas, "Power System Stabilizer Based on Global Fuzzy Sliding Mode Control", Balkan Journal of Electrical and Computer Engineering - (BAJECE) Vol.1, No.2, 2013.

[15] R. Latha, S. Kanthalakshmi, J. Kanagaraj, "Design of Power System Stabilizer using Fuzzy Based Sliding Mode Control Technique", arXiv, Bibcode: 2014arXiv1407.0003L , 2014.

[16] Ngoc-Khoat Nguyen, Intelligent Power System Stabilizers Using Fuzzy Logic Technique and Sliding Mode Control Strategy, International Journal of Innovative Technology and Exploring Engineering (IJITEE) ISSN: 2278-3075, Volume-8 Issue-10, August 2019.

[17] Mohamed Jalaluddin, H. V. SAIKUMAR, BANSILAL,. "Fuzzy Logic Based Power System Stabilizer with Synthesized Accelerating Power as Input signal", International Journal of Electrical and Electronics Engineering Research (IJEEER) ISSN(P): 2250-155X; ISSN(E): 2278-943X Vol. 4, Issue 2, pp 357-364, Apr 2014.

[18] Tayal, V. K., et al. "Power system stability enhancement using fuzzy logic based power system stabilizer." Proceedings of the Third International Conference on Soft Computing for Problem Solving. Springer, New Delhi, 2014

[19] Javad Ansari, Ali Reza Abbasi, Mohammd Hossein Heydari, Zakieh Avazzadeh, "Simultaneous design of fuzzy PSS and fuzzy STATCOM controllers for power system stability enhancement",Alexandria Engineering Journal, Volume 61, Issue 4, 2022, Pages 2841-2850, ISSN 1110-0168.

[20] Hayfaa Mohammed, Marizan Sulaiman, Mohammed Rasheed, Rosli Omar and Shahrieel Aras and Ahmad Fateh, "Stability studies of fuzzy logic based power system stabilizer in enhancing dynamic stability of a two generators tie-line system", ARPN Journal of Engineering and Applied Sciences, VOL. 12, NO. 5, pp16621669, MARCH 2017 ISSN 1819-6608.

[21] Agus Siswanto, Arif Sumardiono, Endang Prihastuty. "Design Fuzzy Logic Controller PSS (Power System Stabilizer) to Stability Improvement of Wind Turbine Penetrated on South Sulawesi Transmission System", The 7th Engineering International Conference on Education, Concept and Application on Green Technology (EIC 2018), pp 234-239, ISBN: 978-989-758-411-4.

[22] B. Kalyan Kumar," Power System Stability and Control", NPTEL,2014.

[23] D. K. Frederick and J. H. Chow, Feedback Control Problems using MATLAB and the Control System Toolbox: Brooks/Cole, 2000.

[24] IEEE Recommended Practice for Electric Power Distribution for Industrial Plants, IEEE 141-1993. 